\title{
Infancia, niñez y adolescencia, en la obra de Horacio Quiroga ${ }^{1}$
}

Topo el mundo sabe que Horacio Quiroga escribe sobre grandes temas de la vida -amor, locura, muerte-. Todos saben que escribe a veces dentro de las dimensiones ordinarias de la vida de todos los días y otras veces deja volar su fantasía entre los sueños de la imaginación. Pero no todos se dan cuenta de que cualquiera que sea su manera hay grandes posibilidades de que emplee a la gente menuda o a la juventud para dar mayor efecto al trabajo, mayor importancia al sentido afectivo de su obra, más relieve al problema estudiado.

Naturalmente al lector casual no le llama la atención la frecuencia con que Quiroga emplea a los niños, para lograr los efectos que desea; pero esto le salta a la vista a quien lee la obra entera del maestro. En cuarenta escritos, por lo menos, figuran jóvenes de varias edades. Aquí nos proponemos estudiar el papel que desempeñan. ${ }^{2}$

Primero debemos decir que cuando Quiroga se refiere a los niños lo hace con conocimiento de causa. Era padre de familia ${ }^{\mathbf{3}} \mathrm{y}$, por más señas, de aquellos que tienen que ocuparse de sus hijos. Y no sólo tenía que ocuparse de ellos sino que quería hacerlo. Consideraba la educación de sus hijos como algo especial del padre. Aquí y allá en sus obras se leen pequeños párrafos, pequeñas frases, que indican la fraternidad de Quiroga con los que hemos andado por el camino del "más grande encanto conyugal." 4

Metámonos ya en harina, como dijo el autor de El sombrero de tres picos, siguiendo paso a paso a los hijos espirituales de don Horacio, mientras recorren las varias etapas de la juventud. 
No habla mucho Quiroga de los peligros del parto y esto me extraña, dadas las posibilidades dramáticas del asunto y las ideas muy fijas que tenía, al menos al principio, acerca de este momento de la vida humana. ¿Qué cosa más natural el fenómeno! Una manifestación de la naturaleza que no debiera preocupar a nadie. Absurdo todo eso de médicos, parteras, enfermeras, hospitales, etc. ¿Quién habla de peligros? Y así en efecto vemos que el primer hijo de Quiroga nace - según los deseos del padre - en Misiones y sin la ayuda de esa gente molesta que suele ocuparse de tales cosas. Pero que Quiroga sufrió momentos de duda se puede asegurar, y que el fenómeno "perfectamente natural" no resultó tan fácil como se lo había imaginado, se adivina por el hecho de que su mujer se trasladó a la ciudad antes de que naciera el segundo hijo. Tal vez recuerde Quiroga su propio estado, al escribir en uno de los cuentos "El chico nace ... y se duerme, mientras el padre, más cansado que la abuela, la tía y la partera juntas..." (El machito, xir). Cualesquiera que hayan sido sus experiencias personales, el hecho es que Quiroga menciona poco el parto, como ya indicamos. En el Corto poema de María Angélica (vi), se hace referencia a un aborto y en la novela Pasado amor Quiroga refiere la muerte de sobreparto de la mujer de Morán, el protagonista, en condiciones semejantes a las del nacimiento del primer hijo suyo. Para el argumento de la historia el hecho no tiene mayor importancia, pero como Quiroga es, él mismo, el Morán de la novela, la cosa no carece de interés. Muestra un aspecto interesante de la obra de Quiroga, es decir, el público examen de conciencia a que se somete muchas veces. Aquí parece sufrir Quiroga de un complejo de culpabilidad y revela que había pensado mucho en los peligros a que expuso a su mujer.

De los infants, como se dice en inglés para indicar a los muy pequeños que no andan, ni hablan, ni piensan, Quiroga habla un poquito más, dándoles el papel que les corresponde en la literatura. No hay drama interior aquí y el único interés que tienen estos chiquitos para el escritor es el efecto que producen en los mayores y tal cual referencia a uno de los grandes misterios de nuestra vida: el sufrimiento de los inocentes. Veamos unos cuantos relatos de este grupo. Como miembro de la gran confraternidad de los padres de familia, escribe Quiroga en dos o tres. $\mathrm{Y}$ hay que ser un miembro así, para sentir a fondo la verdad de los cuentos. El padre de fa- 
milia sufre no en proporción a la gravedad absoluta del caso que afecta a su hijo sino en proporción al amor que siente por él. Esto lo comprendió Quiroga perfectamente y. lo demuestra de una manera poco seria, en varios relatos.

Así en el que se llama Cuento para novios (v) : ¿Qué fué todo, en fin? Un pequeño detalle de la felicidad doméstica; pero cualquiera hubiera creído que era una erupción volcánica." El detalle seguramente parece inocente: "... el chico de los Gaztambide lloraba!" Como huésped en la casa, el autor observa a Gaztambide y su mujer que acaban de pasar una nuit blanche. Fríos, cansados, exhaustos ven al huésped con "una mirada infinitamente tierna $y$ compasiva..." ¿Cuál es la explicación del estado de los padres y de la mirada que dirigen al huésped? Han cometido los esposos la falta mayúscula de dejar dormir al niño a la oración. Habla Quiroga, el pater familias, "Ahora bien: la primera indicación que una madre avezada hace a su joven amiga es esta: "Sobre todo no lo deje dormir a la oración. Le dará, si no, una noche imposible." A la una se despierta el niño de los Gaztambide absolutamente sin ganas de dormir. ¿Qué remedio? "No ignoraban los Gaztambide que lo único sensato en estos casos es levantarse y pasear al chico una hora." Pero ¿con mucho sueño? ¿Con tanto frío? Cualquier otra cosa es preferible. ¿Mover el coche-cuna? ¿Cantar? "Lo fundamentalmente vicioso del sistema es que el niño lloraba simplemente porque no tenía sueño." Pero pasemos a la etapa próxima y lógica. No pudiendo dormir, el buen Gaztambide se pone a analizar el caso. ¿Quién tiene la culpa? La mujer, naturalmente. No hay mal que por mujer no venga y así lo explica Gaztambide a su mitad. Lágrimas. Pobre papá. "-iQué noche! —se dijo desalentado-. Por suerte, no ha de faltar mucho ya." Pero ¿qué descubre después de levantarse para ver el reloj del comedor? "Eran apenas las dos." Recriminaciones. "Sí, ya sé que estás harto de mí..." Lágrimas. Sollozos. Imposible leer. Por fin duerme el niño. "- - Falta mucho? -No, va a amanecer... Aprovecha ahora. - No tengo sueño..., no podría." Y quebrado él, muerta de inercia ella, es como encuentra el huésped al matrimonio cuando "pensando en mi candor de soltero extrañado por el motivo de la terrible noche, acababa de mirarme con infinita ternura." ¿Cómo explicar el caso a un pobre diablo $\sin$ hijos? 
Si he entrado en tantos detalles al examinar este cuento es para indicar una manera de Quiroga que es tan deliciosa como son poderosas $u$ horribles o profundas otras. Verdaderamente qué "erupción volcánica" ha hecho Quiroga de tan poca cosa como la falta de sueño de un niño.

En El machito (XII) vemos un problema paternal semejante. Otra vez se trata de un padre frente a una circunstancia no comprendida en toda su gravedad hasta después de nacido el hijo. “... concluído el peligro y excluida toda inquietud, surge de repente una verdad franca, lisa y evidente que los padres no habían sospechado siquiera: que los chicos efectivamente gritan y rabian." El "machito" en cuestión no pierde tiempo en declarar a los cuatro vientos su horario. "... concluída la teta, el machito dormía cinco minutos, lloraba diez, gritaba cuarenta, y rabiaba de nuevo diez, hasta que se dormía de fatiga otros cinco minutos." Sólo los que no hayan conocido les quinze joies de mariage creerán que sólo es literatura lo que dice Quiroga después: "Estas situaciones ... tienen el singular privilegio de provocar en el padre dos deseos fulminantes: el de arrojar el machito por la ventana, y tras él cuanto dista menos de un metro de sus brazos; y el de hundirse bajo tierra para preguntarse hasta el fin de los siglos cómo pudo ser tan inmensamente estúpido para haber deseado aquello." Menos mal que el niño duerme por la noche y que el padre no tiene que estar en casa durante el día. Pero llega la Semana Santa y le dan a papá licencia por toda una semana. iQué horror! "En vano su mujer hacía lo posible para echarlo de casa. $\mathrm{El}$, con la absurda terquedad de todos los padres, se empeñaba en quedarse a sufrir, y hacer, desde luego, sufrir a los demás." Por fin el hombre apela a los recursos de homo sapiens e inventa un monstruo de zinc que disfrazado de mujer y calentado por dentro con tubos de agua caliente hace las veces del pecho de la madre "...y si es verdad que... los padres, en silenciosas cuclillas detrás del sillón, tienen que balancear constantemente la máquina, el chico no llora, y es éste un triunfo que únicamente pueden apreciar los padres cuya esperanza de loca felicidad fué tener un machito rabioso."

Esta manera literalmente familiar de escribir no es, por supuesto, la más común en Quiroga y no nos sorprende encontrar que aun tratándose de los niños más pequeños aparece el tema trági- 
co de la vida. Así es que en el cuento titulado La reina italiana (Iv) la hija de Kean es atacada horriblemente por un enjambre de abejas mientras se queda acostada en la cuna. "No había allí sino un cuerpecillo de bebé con una monstruosa bola de carne por cara, en que boca, nariz y ojos desaparecían en una vejiga lívida." Afortunadamente le salvan la vida a la pequeña, pero cuando por fin se recogen las abejas furiosas:

Kean se estremeció entonces libremente. Lo que había querido decir a su mujer es que posiblemente los ojos de la criatura estaban tocados...

La sombra crecía; y en la súbita frescura Kean, sacándose el sombrero con el velo, arrojó en un brusco suspiro crepuscular la fúnebre opresión de toda esa tarde que se llevaba, en gigante pesadilla de abejas, la vida de su caballo y la belleza de su hija.

Aparecen niños de pecho también en Los cementerios belgas (IV). Este cuento es casi único en la obra de Quiroga. Como ha dicho John Crow: "Por primera y única vez en su vida de escritor presenta algo de un definido e inminente significado social." 5

E1 relato es de los más terribles que ha escrito Quiroga. Es una protesta violenta contra la brutalidad de la guerra, crimen contra Dios y el hombre. La escena ocurre en Bélgica durante la primera guerra mundial. Pasa por una de las carreteras del país una columna de fugitivos. Todos sufren, pero especialmente los niños. "Los pequeños recién salidos del pecho materno, y sin poder tomar una sola gota de leche, sufrían de enteritis desde el primer día."

Seguimos paso a paso esta columna que se detiene sólo para enterrar a los que han muerto desde el último alto. Vemos el terror de las madres que ven acercarse a sus niños el espectro de la muerte, el horror que tienen al ver que no hay nada que darles de comer o de beber. Cunden entre las criaturas las enfermedades, como el fuego en un bosque donde no ha llovido desde hace mucho. Por fin deciden montar a las mujeres y a las criaturas en los pocos caballos que hay, $\mathrm{y}$ aquéllas avanzan más rápidamente; pero llega un destacamento de caballería belga con órdenes de requisar todos los caballos disponibles. $\mathrm{Y}$ otra vez se ven a pie las mujeres con sus criaturas : 
Más allá, muy cerca tal vez, estaba la población salvadora, en su felicidad de ropa seca y leche caliente. Pero entre tanto el fúnebre convoy, cementerio ambulante de criaturas de pecho, quedaba desamparado en la carretera sombría y espejeante de agua, bajo la lluvia hostil que iba matando en flor, implacablemente, los retoños salvadores de una nueva Bélgica.

La amargura de este cuento se debe en gran parte al hecho de que las víctimas sean unos niños completamente libres de pecado. El sufrimiento de los grandes no se comprende a veces, pero se aguanta. El sufrimiento de los pequeños ni se comprende ni se aguanta.

Nos toca ahora hablar de los niños en la primera y en la segunda infancia, es decir, de los preadolescentes. Muchísimo se ocupó Quiroga de ellos. Del carácter moral de los niños de la primera infancia no tenía muy alta idea, que digamos, y nos da su opinión en Las mujercitas (xII):

... de esas personitas no he querido sino recordar el profundo egoísmo, de una profundidad tan clara, ingenua y espantosa, como no se la volverá a hallar jamás en la edad viril. Estoy a mi vez convencido de que los chicos, desprovistos de sus bucles, su gracia y encantos de pequeños monos hermosos y entretenidos, no valen absolutamente nada, y que, por contra, el hombre de moral más desgraciada conserva un exceso de bondad y altruísmo comparado con esas bestiezuelas divertidas que encarnan a un grado exasperado el egoísmo brutal, sin compasión de ninguna especie, inherente a su condición de cachorros... IPero indudablemente! iLos quiero mucho! Solamente que yo, en mis hijos, quiero al futuro hombre, y ustedes, las madres, al monito entretenido del momento.

¿Caveat lector! i $\mathrm{El}$ hombre es algo farsante! Tan poco valen los monitos que no sólo se ocupa Quiroga de la edtucación seria de los suyos sino que juega con ellos. Tan poco valen los niños que los esparce por todas partes, en sus cuentos. Tan poco valen los pequeños que para ellos especialmente escribe sus famosos Cuentos de la selva (para niños). $\mathrm{Y}$ tan poco le interesan las pequeñas criaturas que vive rodeado no sólo de sus propios hijos sino también de animalitos de todas clases a los que hace hablar en sus cuentos, con tanto amor y tanta ternura que es imposible no fijarse en lo mucho que este hombre deba de haber querido a los pequeños. 
Claro que éstos, como los grandes, tienen que sufrir la ley de la vida, y esa ley es la de la presencia de la muerte. La muerte, de importancia capital para cada ser humano, es una obsesión en Quiroga. Por eso no sorprenderá a nadie encontrar en este autor una serie de cuentos donde mueren varios niños, por causas muy distintas las unas de las otras. En todos estos cuentos nos encontramos frente al problema del porqué de estas muertes. En la vida no hay respuesta al problema. En el arte tal vez la hay. El autor quiere dar la idea del sufrimiento y del dolor. ¿Qué cosa más adecuada hay para sugerir un alto grado de dolor que la muerte de un niño querido? Y lo que hace sufrir a los padres no sólo es el hecho consumado sino la posibilidad de que la muerte pueda llegar de cualquier lado, en cualquier momento, sin que la edad ni la inocencia de la víctima tenga nada que ver con ello.

No siempre desarrolla Quiroga el tema de la muerte. A veces sólo se refiere a él. Así hace referencia en el Corto poema de María Angélica (vi) a "...la desgraciada muerte de una pequeña amiga de Juana, a quien un carruaje arrolló cuando iba a dar sus primeros exámenes." Esta niña no tiene nada que ver con el argumento. Lo interesante es que se le ocurrió a Quiroga introducir el detalle. En Pasado amor encontramos la frase "Perdió de muy pequeña a su madre y a su hermanita en un terremoto." Otra vez lo importante no es el hecho, que no contribuye nada a la historia, sino la alusión a la omnipresencia del peligro que nos rodea a todos.

A veces la muerte del niño es el centro de la acción. En Los cazadores de ratas ( $\mathrm{I}$ ), por ejemplo, se trata de una pareja que vive en el campo con un hijo único. El pequeño muere un día, a causa de la mordedura de una serpiente. En El infierno artificial (vI) mueren todos los niños de una familia, de resultas del contagio de la difteria. Así es que tenemos desastres de la naturaleza, enfermedad, peligros del campo, etc., como motivos de la muerte de los inocentes niños de estas historias. Pero siendo Quiroga quien es hemos de esperar que introduzca aquí, como en otras partes, lo sobrenatural y la locura. $\mathrm{Y}$ así es, en efecto. En el relato $L a$ intervención de los espiritus y la caja de fósforos (XII) Quiroga discute un caso ya analizado por Maeterlinck. ${ }^{7}$ Se trata de una madre que es viuda. Pone todo su amor, toda su fe, se podría decir, en un hijo de cinco años. Pero una voz misteriosa del otro mundo le sugiere que cuanto 
haga será inútil. A pesar de todo, el niño morirá. Obsesión de la madre. El fuego es el peligro. Quita todos los fósforos. 'Vuelve el colchón' dice la voz misteriosa pero no dice cuando. La madre tiene que salir del cuarto en aquel momento. Regresa para encontrar al niño quemado, a punto de morir. ¿Por qué no dijo la voz cuándo la madre debiera volver el colchón? ¿ Por qué prevé el peligro sin dar la alarma? Misterio. Tanto impresionó a Quiroga la idea de esta tragedia que la reconstruye en un cuento que titula El llamado (I). Cambia el argumento de esta manera. La madre ha prometido al padre muerto proteger a su niña de los peligros de este mundo. La voz le dice que sus esfuerzos serán inútiles: el fuego matará a la muchacha. Observa toda precaución la madre, pero la niña halla un nuevo juguete, el revólver de su padre. Se pone a jugar con él y sigue el resultado inevitable. Sólo nos queda por dar un detalle. La madre ha reconocido la voz misteriosa. Es la del padre muerto. No nos sorprende que Quiroga imagine que estamos en un sanatorio escuchando el relato de los labios de la madre, internada por ser "un caso de obsesión y de alucinación auditiva como pocas veces se presentan igual."

El último caso que debemos considerar en este grupo de cuentos, que se relaciona con la muerte en la primera infancia, es aquella maravilla de La gallina degollada (I). Es una manifestación del gran interés que tenía Quiroga por lo anormal. La muerte llega a una niña de cuatro años, cuando sus hermanos idiotas, habiendo visto degollar una gallina a la criada, resuelven llevar a cabo semejante experiencia ellos mismos, siendo la víctima su hermanita. Se puede imaginar sin dificultad lo que representaba para los padres una niña normal, después del fracaso de sus cuatro hijos locos, y su horror al darse cuenta de lo que ha pasado.

A veces Quiroga consigue sus efectos no con la muerte misma sino con la inminencia de la muerte. Así en Los fabricantes de carbón (III) logra hacernos sentir la tensión terrible de dos hombres mayores frente a la grave enfermedad de una chica de cinco años por quien ellos solos responden. La chica sana, pero ellos han estado en presencia de la muerte. $\mathrm{Y}$ en $\mathrm{El}$ desierto. (IV) el lector queda horrorizado ante la muerte cierta que espera a unos chicos de cinco $\mathrm{y}$ seis años de edad. 
Merece atención especial $E l$ desierto porque es una de aquellas narraciones en que Quiroga parece hablar de sí mismo. Se trata de Subercasaux (se ve que dentro de ciertos límites éste es Quiroga) que vive solo con sus hijos. Son estos "hechura suya en sentimientos y educación." Muerta la madre, él ha tenido que formarlos y lo ha hecho a su manera. "Las criaturas, en efecto, no temían a la obscuridad, ni a la soledad, ni a nada de lo que constituye el terror de los bebés criados entre las polleras de la madre... No temían a nada, sino a lo que su padre les advertía debían temer...;" $\mathrm{Y}$ de tal manera han sido educados que ya no hay peligro. "Conocian perfectamente - como toda criatura libreel alcance de sus fuerzas, y jamás lo sobrepasaban." Pero esto no ha sido fácil y a veces el padre tiene dudas. "-Un día se me mata un chico - decíase-. Y por el resto de mis días pasaré preguntándome si tenía razón al educarlos así." Subercasaux es compañero de juegos, maestro, amigo de los chicos. Pero he aquí que un día un piquete le trae una infección en un dedo del pie derecho. A1 mismo tiempo vienen lluvias increíbles, crecen los ríos y la pequeña familia se ve aislada, sin posibilidades de comunicación con los de afuera. De mal en peor va la infección de Subercasaux. Llegan fiebre, delirio. $\mathrm{Y}$ de repente se da cuenta de la verdad horrible de la situación. "¡Pero no tendrán qué comer!" Llegan los últimos momentos. Subercasaux trata de darles valor a los niños. Muere: Los chicos se quedan solos:

Sólo la mujercita, con una vislumbre de la extensión de lo que acababa de pasar, hacía a ratos pucheros con el brazo en la cara, mientras el nene rascaba distraído el contramarco, sin comprender.

$\mathrm{Ni}$ uno ni otro se atrevían a hacer ruido.

Pero tampoco les llegaba el menor ruido del cuarto vecino, donde desde hacía tres horas, su padre, vestido y calzado bajo el impermeable, yacía muerto a la luz del farol.

Así vivió Quiroga con sus propios hijos, después de la muerte de su mujer, y si no murieron ni él ni sus hijos como en el cuento, no cabe duda de que la posibilidad lo haya preocupado.

Muy poca cosa ha dicho Quiroga en todos estos cuentos de la naturaleza, de estos pequeños de la primera infancia. Lo que 
a él le interesa es la psicología de la gente. Vista su ya citada actitud de que los pequeños no valen nada moralmente, no podemos esperar que trate de penetrar en su psicología. Apenas se asoma alguno que otro de estos chicos a la vida consciente con tal o cual "vislumbre", como la chica de El desierto. L.os demás son inconscientes como el hermano de ella. Los niños muy pequeños sirven solamente para dar relieve especial al espectro de la muerte, formidable en todo caso, horrible cuando se trata de los que apenas comienzan a vivir. $Y$ no sólo hemos de pensar en el horror de la muerte de los inocentes sino también en el sufrimiento de los que quedan. Aquéllos al menos ya no surren. Esa es la parte de los padres y los parientes, víctimas de su amor para con los chicos. Porque para Quiroga quien dice amor dice sufrimiento también. ${ }^{8}$

A pesar de la sombra negra de la muerte, presente en cada momento de la vida humana, algunos niños crecen y entonces es cuando empiezan a aprender lo que es la vida. La madrugada de la vida conseiente, el amanecer del concepto de la realidad, la mañana del duro aprendizaje del vivir, tal es el tema de otra serie de cuentos, y, como es de suponer, los niños ya son un poco más grandes, la vida interior se ensancha, el cachorro se cambia en hombrecito.

No hace falta decir que la existencia de los hombres es triste y que sus lecciones apenas valen la pena de aprenderlas. El fin de la vida es la muerte. Ahí está la verdad de las verdades, la cosa que todo ser viviente ha de admitir. Pero es duro y hace sufrir. De esto se dan cuenta los chicos de Yaguaí (II), cuando por casualidad su padre mata al perro querido. $Y$ hay que aprender que no sólo mueren los animales queridos sino seres humanos también. Seres amados, a veces. $\mathrm{Y}$ esa es la lección que va a aprender el niño de $E l$ hombre muerto (II) cuyo padre, trabajando en el bananal, ha caído sobre su machete. Ya terminaron los sufrimientos del padre (ha dejado de ser hombre); pero ya empiezan los del chico (pronto será hombre) que se acerca con el grito familiar de siempre: " $\mathrm{iPia-}$ piá!" Es esa una manera horrible de saber lo que es la muerte, pero hay otras. Tal, por ejemplo, la más brutal de esa cosa curiosa que los mayores han dado en llamar civilización. Así es el caso de los hijos de don Malaquías Sotelo, juez de paz de Iviraromí. Muere el papá y. se acerca el momento de despedirse: 
La tarde caía ya y se clavó aprisa el cajón. Pero no sin que antes viéramos venir a Elena trayendo a la fuerza a sus hijos para que besaran a su padre. El chico menor se resistía con tremendos alaridos, llevado a la rastra por el suelo. La chica besó a su padre, aunque sostenida y empujada de la espalda; pero con un horror tal ante aquella horrible cosa en que querían viera a s̀u padre, que a estas horas, si aún vive, debe recordarlo con igual horror. (La cámara oscura, Ir.)

Una cosa que-hay que aprender es que la vida es hipocresía. Los pequeños creen todo lo que les dicen las personas mayores. Desgraciadamente, mucho de lo que creen aquéllos, con este título, no es verdad y el sufrimiento que acompaña la revelación de la mentira de los grandes es harto desconsolador, especialmente si la mentira proviene de las personas en quienes los chicos han depositado el amor - los padres y los maestros. Quiroga ha estudiado el caso de la desilusión de una chica, en La igualdad en tres actos (XIII). Vale la pena narrar el caso. Se trata de una nueva alumna de la escuela normal (Quiroga había sido profesor en tal escuela). Es una pobre que llega mientras la clase de niñas acomodadas aprende la lección del día: “... debemos respetar a nuestros semejantes... iPorque todos somos iguales!... Desde el ministro, hasta el carbonero, a todos debemos respeto." La chica vuelve a casa muy triste. "Su padre era carbonero." La niña no es capaz de analizar la frase que ha oído; pero instintivamente sabe que hay algo en esa hasta que destruye el valor del sentimiento expresado. "-Hasta papá es digno de respeto- se repetía la chica." Cuenta el caso al padre. Este es un curioso impertinente que sugiere lo siguiente a su hija: "Dime ¿tú sabes en qué consiste esa igualdad de todos los hombres...? Pues bien, pregúntaselo a ella [la maestra] en la primera ocasión. Quisiera saber qué dice." Y así lo hace la inocente niña. Le contestan solamente con risa. ". . desorientada ya y dolorida" la niña le hace la misma pregunta al padre, sin aprender mucho más sobre el asunto:

-Y ¿en qué somos iguales, papá?

- ¿En qué, mi hija? ... Allá te habrán respondido que por ser todos hijos de Adán, o iguales ante la ley o las urnas, [i] qué sé yo... [!] 
Pasan los días y se prepara una fiesta para celebrar el jubileo de la directora de la escuela. Se presentarán las niñas con ramos de flores y ofrecerán el mejor a la directora. Se reparten las tarjetas de invitación, pero alcanzan sólo a las niñas bien vestidas. El padre comprende, y manda a la niña con un ramo incomparablemente mejor que los demás. Orgullosa, la pequeña tiembla de emoción. Pero cuando llega el gran momento "... la profesora de su grado, después de acariciarla, tomó el ramo de sus manos y lo colocó entre las de la hija del ministro de Instrucción Pública, condiscípula suya. Esta, entre frenéticos aplausos, lo ofreció a la directora enternecida." Frente al dolor de su hija, el padre le confirma la lección brutal: "-Llora, pequeña, llora; eso tenía que pasar, era inevitable. .... Es que nadie, ¿oyes? nadie, desde tu directora hasta la última ayudante, nadie cree una palabra de toda esa igualdad que gritan todo el día!' ¿Aprendió bien la niña? Sí, aprendió bien porque ya es grande y se presta a la hipocresía de los grandes. Lo sabemos porque ella es quien le contó esta historia a Quiroga terminando sus recuerdos así: "iPobre papá! Era muy inteligente. Pero mis alumnos saben muy bien, porque no me canso de repetírselo, que desde el ministro hasta el zapatero, todos somos iguales..."

$\mathrm{Si}$ he entrado en detalles al examinar este cuento es porque a mi modo de ver el desarrollo del argumento demuestra a la perfección el don maravilloso que tenía Quiroga de hacer mucho de poco. El hecho en sí es insignificante. El truco está en amoldarlo de tal manera que el lector, si no sufre literalmente con la niña, al menos tiene que recordar algún descubrimiento igualmente penoso de la propia vida. También, a propósito, contribuye el cuento algo a nuestro mejor entendimiento del amor de Quiroga para con la selva. Ya conoció él la civilización. Entre la ferocidad de los hombres y la del desierto prefiere ésta. Al menos, no hay tanta hipocresía en la selva.

En tres historias introduce el tema de amor aun con motivo de estos niños de lo que se podría llamar la segunda infancia. De esta precocidad en el amor sufrió Quiroga cuando niño, según sus amigos intimos, pues que dicen que "... en el terreno de la precocidad sentimental, tan complicado y propio, Quiroga entraba con gran conocimiento de causa, porque, según lo hemos dicho ya, desde 
la madrugada de la vida el amor comenzó a hacer experiencias sobre su alma." 9

Consideremos Silvina y Montt (Iv). Montt vuelve del desierto con cuarenta años encima, para hallar otra vez a la niña de ocho años que se sentaba en sus rodillas hace diez años. Pero resulta que la niña - ya no es niña. Montt evoca el pasado. "Nunca, sin duda, fuera un hombre objeto de tal predilección de parte de una criatura." En casa lo conocian como "El amigo de Silvina" y buenos amigos eran, en efecto, aunque duró poco tiempo la amistad puesto que Montt se fué al campo. Ya ha vuelto y no tarda en enamorarse de Silvina. Siguen meses de duda, hasta que llega una carta llena de amor y de pasión. Nunca hubo otro amor para Silvina. Todos le habían parecido pálidos ante la imagen fiel y constante de su Montt. "Amor mío: te ama... y te espera... S."

Otro caso parecido es el de Rea Silvia (vI). Sólo que esta vez subraya Quiroga más el sufrimiento que acompaña el amor. "Hay en este mundo naturalezas tan francamente abiertas a la vida que' la desgracia puede ser para ellas el pañal en que se desenvuelven al . nacer." Así la niña que da su nombre al cuento. Rea es "una criatura voluntariosa" con una "alma expuesta al desquicio." Celos y pasión se muestran temprano en ella. "Yo digo: [i] almas de niña que en Rusia enloquecen a los escritores!" Pues bien, la persona que cuenta la historia había sido en aquel entonces el novio de la hermana mayor. Pero quien lo quería con pasión era la pequeña. "Todos los días, cuando yo llegaba, corría a colgarse de mi cuello. Me besaba largamente los ojos." Imposible mantener las cosas en su lugar con esta apasionada. Una nadería suelta una declaración en toda forma, por parte de ella: " $\mathrm{S}$, te quiero, te quiero mucho! - Me besaba la cabeza, los ojos- ¿por qué me haces sufrir? -Y repetía únicamente, sacudiendo la cabeza, con los ojos cerrados, quejosamente: -i Sí, te quiero, te quiero!" Y en efecto, la chica se enferma ante la imposibilidad de su amor, "como si la pequeña apasionada llama de su vida se hubiera encendido prematuramente con mis besos ..." Hasta tal punto llega el estado neurótico de Rea, que la muerte asoma. Por fin una noche, cuando están solos, le pide un beso a su amado: 
- Un beso como si fuera... -Y cerró los ojos.

- Como si fuera... -Volvió a abrirlos lentamente. Apenas:

-... Teresa...

Hombre y todo me puse pálido. No dije nada: me incliné temblando a mi vez y uní mi boca a la suya. Para ella fué tan grande esa dicha de completa mujer que se desmayó. Por mi prte puse en su boca el beso de más amor que haya dado en mi vida.

Pero no murió Rea. Pasaron los años y es ahora una señorita de dieciocho años. ¿Queda algo de su amor?

La miro largamente; ella no. Se va. Al llegar a la puerta, vuelve lentamente la cabeza y me dice siempre en suave burla:

-Di: ¿ no me harás morir de pena como antes?

; Ah! isi a pesar de esa burla estuviera seguro de que en Rea ha muerto todo!...

Surge el mismo tema en la novela Historia de un amor turbio. Aquí se trata de Rohan, un joven de veinte años, amigo de los Elizalde a quienes visita con frecuencia. Hay varias muchachas en la familia. Por ahora, quien nos interesa es la pequeña Eglé, niña de nueve años (la propia hija de Quiroga se llamaba Eglé). Rohan la ve en la calle de vez en cuando, le habla, y a veces la besa. Por supuesto, se trata de una especie de juego. Los besos están destinados a Mercedes, una hermana mayor. La víspera de su partida para Europa, Rohan hace una visita de despedida a la familia. Eglé no se halla en estado normal, y le declara su amor. Pero no es la declaración propia a una niña de nueve años:

-Lo querré siempre - continuó, casi por llorar. Rodeó con su brazo el cuello de Rohan y se mantuvo así estrechada a él. Rohan, conmovido sin quererlo, le preguntó en voz muy baja:

-Y cuando seas grande, ¿me querrás?

Ella sacudió la cabeza como las mujeres, cuando la pregunta es dolorosa a fuerza de evidencia:

-Sí, sí...

No respondió, pero unió más su cara a la de él, estremecida. ¡Sus ojos, llenos de lágrimas, contaron a la luna lejana esa insuperable dicha que nunca, nunca había de llegar! No hablaba ya, abrazándole siempre y con su mejilla húmeda apretada a la de él.

Rohan no sabía que hacer. ¿Qué decirle? Sentíase un poco en ridículo, $\ldots 10$

$\mathrm{Y}$ a la hora de despedirse "... la criatura lo miró tan desconsoladamente que sintió vergüenza y la besó, serio." ${ }^{11}$ 
El viaje de Rohan duró ocho años; pero, como veremos más tarde, Eglé nunca olvidó este primer amor. ${ }^{12}$

Dado el gran interés que tenían para Quiroga los casos raros y aun los puramente fantásticos, no nos sorprende ver que sale de los límites de lo normal en Berenice (XI). Quiroga aquí deja atrás lo creíble, para demostrar la intensidad de pasión de una de las almas precoces que le interesaban tanto.

Esta vez el narrador es el gran músico Wagner que visita un salón de París; en 1842. Allí encuentra a una criatura llamada Berenice $\mathrm{y}$ de edad de nueve o diez años. Baudelaire le explicó a Wagner que la muchacha "sufría de crisis nerviosas muy fuertes y muy raras sobre todo. Sobre todo, muy raras. Algo de catalepsia o cosa así." Cualquiera que fuera la circunstancia, la muchacha se apasionó por la música de Wagner. Tanta era su sensibilidad, que sufría ataques al oír tocar al maestro, hasta que una noche, sentada la pequeña en las rodillas de Wagner, escuchó una partitura nueva. Mientras tocaba el músico, la muchacha cambiaba visiblemente. Destrozada el alma de niña, apareció la "mujer radiante de juventud, de ojos ensombrecidos en demente fatiga." Temblaba la muchacha mientras avanzaba la partitura y vieron que "...la sombra de sus ojos bajaba ahora del párpado, desmenuzándose en una fina redecilla de arrugas... no quedaba ya ni rastros de la mujer de veinte años, evaporada, quemada en un cuarto de hora de aquel vértigo de pasión."

Sigue la partitura, hasta que nos dice Wagner: "Vi que la redecilla de arrugas invadía ahora todo el rostro, que su frente estaba ajada, y noté de golpe que ya no quedaba ni rastros de la mujer de cuarenta años, agotada por una vida entera, [sic] de pasión, calcinada en treinta minutos por la explosión de alaridos salvajes que había cerrado la partitura." $\mathrm{Y}$ por fin terminó la tortura:

Todo estaba concluído. En mis brazos, inerte, helada, en catalepsia, o no sé qué, tenía ahora una lamentable criatura decrépita, llena de arrugas.

Tenía once años. En el espacio de hora y media, había quemado su vida entera como una pluma en aquel incendio de pasión..." 13 
Al hablar de la muerte entre los niños de la primera infancia mencionamos La gallina degollada (I). Además de la niña que muere en el cuento hay en la familia cuatro hijos, idiotas. E1 menor de ellos tenía ocho años; el mayor, doce. Generalmente pasaban "Todo el día, sentados en el patio... Tenían la lengua entre los labios, los ojos estúpidos, y volvían la cabeza con toda la boca abierta." Estos locos destruyeron casi la vida de los padres que se hacían recriminaciones culpándose el uno al otro por haber producido tales monstruos. Estos "Animábanse sólo al comer, y cuando veían colores brillantes $\mathfrak{u}$ oían truenos. Se reían entonces echando afuera la lengua y ríos de baba, radiantes de frenesí bestial. Tenían, en cambio, cierta facultad imitativa ; pero no se pudo obtener nada más." La llegada de Bertita, hija normal, quitó a los locos toda posibilidad de amor paternal. Ellos representaban el fracaso; Bertita, el éxito. "... no hubo ya para los cuatro hijos mayores afecto posible... Pasaban casi todo el día sentados frente al cerco, abandonados de toda remota caricia." Y un día, "animados" por el "color brillante" de la sangre de una gallina degollada por la criada, ellos mismos ejercieron su "facultad imitativa" matando a su hermanita.

La gallina degollada representa bien lo mejor de Quiroga. En pocas páginas prueba su poder gráfico en la pintura de los idiotas, su penetración psicológica en el estudio de los padres, su don dramático en el fin, que le parece al lector horrible pero inevitable.

A veces Quiroga se ocupa de cosas menos serias y así es en unos cuentos del grupo que estamos discutiendo. Nuestro primer cigarro (vi) es una bagatela tradicional, como lo sugiere el nombre. Dos chicos se ponen a fumar en pipa el tabaco de los cigarrillos de st tío. El varón, como es de rigor en tales casos, da principio a la operación :

María, que devoraba mi acto con los ojos, notó que los míos se cubrían de lágrimas: jamás se ha visto ni verá cosa más abominable. Deglutí, sin émbargo, valerosamente, la nauseosa saliva. - ¿Rico? -me preguntó María ansiosa, tendiendo la mano. —Rico -le contesté pasándole la horrible máquina.

Pronto se abandona la pipa con la excusa de buscar nidos de pájaro "para retirarnos prudentemente del tabaco sin que nuestro orgullo sufriera." 
En otra ocasión arreglan los chicos que su tío odiado fume un "cigarrillo pateador", es decir, un cohete rodeado de papel de fumar. Corre el tío furioso tras el muchacho asustado y éste se esconde, después de amenazar con tirarse a un pozo. Antes de desaparecer, tiene el niño la buena idea de echar una piedra al pozo. Horrorizado y completamente engañado el tío; consternación general; desmayo de la madre. Vuelve el joven héroe a su pipa y fuma hasta ponerse enfermo. Por fin lo descubren y lo traen sin sentido a la casa, donde los intereses creados conducen a una especie de acuerdo entre tío y sobrino. Quiroga aquí no busca más que la diversión del lector y el cuento no pide comentario.

Más interesante es la idea de Las voces queridas que se han callado (XII). E1 niño del cuento no tiene importancia en sí mismo. Lo que interesa es la supervivencia del pasado en el presente, esta vez por medio de él. Dos amigos viajan en un tren, en presencía de un niño de diez o doce años. Cuando éste habla, los amigos se miran asombrados. Es una voz "querida", una voz que ambos han oído mucho, aunque ninguno de ellos recuerda en dónde. Intrigado, uno de los amigos se pone a averiguar. Descubre y visita a la familia del muchacho. La madre dice haber conocido al padre del hutésped y por fin la propia madre de éste explica que "La familia había vivido en mi pueblo natal, más o menos en la época del nacimiento de mi amiguito y ella, mi madre, no tenía fuertes motivos para querer a la del chico." Manda el narrador un telegrama a su amigo diciéndole: "Muchacho acaso pariente mio. ¿Qué hacemos de usted?"

Agregamos estas dos narraciones a la larga lista ya formada, sólo para mostrar que aunque el sufrimiento, la locura, la muerte, etc., representen los aspectos de más interés en su obra, no todo lo de Quiroga ha de ser grave y trascendental.

Párrafo aparte merecen de seguro los famosos Cuentos de la selva. Muchos cachorros hay en las páginas de estos cuentos para niños (de todas las edades); no sólo cachorros de hombre sino también cachortos de animalitos, y todos tienen la fascinación de los jóvenes de cualquier especie. Si Quiroga supo aprovecharse de la simpatía que sentimos casi todos hacia los jóvenes, debemos agradecérselo. Truco sentimental si se quiere; pero de un sentimentalismo que en él tiene más de simpático que de empalagoso. Casi nos 
parece razonable que estos animalitos piensen como seres humanos, $y$ es un deleite ver con qué amor habla Quiroga a sus criaturas de aquellas de los animales del campo, del bosque y del río.

Pocas veces en estos cuentos habla Quiroga en tono de sermón. Hay algún que otro consejo, alguna que otra humorística observación de padre de familia: "... los loros, como los chicos, aprenden con gran facilidad malas palabras"; ${ }^{14}$ pero la verdadera lección de amor y de fraternidad no se seca directamente sino del ambiente de amor que lo invade todo. Para demostrarlo nos bastará resumir un par de cuentos.

Había, por ejemplo, una gamita que antes de andar sola aprendió de su madre los "diez mandamientos" de los venados chicos. ${ }^{15}$ Tiempo perdido. Un día come la gamita la miel de unas abejas que no pican. Hace una generalización inmediata: las abejas no pican. Frente a la experiencia ¿qué valen las advertencias de una madre? Sale la gamita al día siguiente a comer miel otra vez. Y esta vez la ciegan las picaduras de las abejas. Llora la pequeña y la madre desesperada la lleva a la casa de un buen hombre que vive al otro lado del monte. E1 hombre les da una pomada y un consejo: ha de pasar la pequeña veinte dias en la oscuridad. "Después póngale estos lentes amarillos y se curará." Pero ¿cómo explica Quiroga que los animales hablen con los hombres? ¿Qué explicación ni qué niño muerto! Cualquier padre y cualquier hijo saben que el amor hace milagros.

Bueno, pues se efectúa la curación. "Pero sólo ${ }^{16}$ la gama supo cuánto le costó tener encerrada a la gamita en el hueco de un gran árbol, durante veinte días interminables." Llega el día de la visita de agradecimiento. Intercambio de cortesías. La gama lleva al hombre plumas de garzas. El hombre le da miel a la gamita. $\mathrm{Y}$ después “... cuando caía la tarde y empezaba a llover, el cazador colocaba en la mesa el jarro con miel y la servilleta, mientras él tomaba café y leía, esperando en la puerta el TAN-TAN bien conocido de su amiga la gamita."

Otro cuento habla de un coaticito que tampoco quiso recordar las advertencias de su madre y que también sufrió por eso. ¿Qué le dijo la mamá? "... que no vaya nunca a buscar nidos al campo, porque es peligroso." 17 Pero es que desgraciadamente el pequeño "... era loco por los huevos de pájaros" y "el deseo pudo más." i He- 
lás! Si encuentra un huevo, también halla una trampa y helo prisionero. Oyen los chicos de la casa la caída de la trampa y todos salen a ver. El padre les da el coaticito a sus hijos y lo dejan en una jaula. ¡Pobrecito! Llora cuando su familia va a verlo a la luz de la luna y al día siguiente lo encuentran los chicos muy triste. Le dan uvas, chocolate, huevos, etc. También le dan un nombre, Diecisiete, por alguno de esos procesos de razonamiento que permaneccerán siempre misteriosos para las personas mayores. Encantado está el coatí, con esta bondad insospechada y es un caso de amor mutuo. Pero una noche muere el coaticito, a cattsa de la mordedura de una serpiente (no sólo a los hombres los rige la ley de la muerte imprevista y fulminante). $\mathrm{Y}$ cuando la familia del coatí llega a visitarlo aquella noche, se sustituye al coatí muerto por otro porque ya todos quieren a los cachorros del hombre y no admiten que se pongan tristes.

Así es el tono de todo este volumen. Tiene el encanto de las cosas simples. Pero es una de esas simplicidades de gran artista, de las que no se imitan con éxito. La idea de la fraternidad entre el hombre y los animales es la herencia que Quiroga deja a sus hijos - a sus propios hijos y a sus hijos espirituales. ¿Qué cosa más auténticamente suya habría podido darles?

E1 estudio de los adolescentes en la obra de Quiroga, revela la misma predilección del autor por los temas de amor, locura y muerte, que se encuentra cuando habla de los niños. Ahora, sin embargo, cambia el tono. Si con los niños de segunda infancia el autor se acerca a la vida interior de sus personajes, aquí se desarrolla dicho tema en toda su plenitud. Cuanto más capaces de sufrir, amar y enloquecer son estos jóvenes, tanto más rico es el campo de investigación psicológica que ofrecen al escritor. Y los peligros y las anormalidades de la vida interior de ellos atraen a Quiroga de más en más.

Por supuesto; en este grupo de cuentos hallamos de vez en cuando alguno que nos recuerda una manera familiar. Tal el bien conocido que se llama El hijo (I). Se trata de un muchacho de trece años que se va solo a cazar dejando atrás al padre que lo ve alejarse, contento con lo contento que está su hijo. Hay que dejarlo ir, ha de hacerse hombre. Pero no por tener esta teoría deja el padre de pensar en el muchacho: 
El fué lo mismo. A los trece años hubiera dado la vida por poseer una escopeta. Su hijo, de aquella edad, la posee ahora; - y el padre sonríe.

No es fácil, sin embargo, para un padre viudo, sin otra fe ni esperanza que la vida de su hijo, educarle como to ha hecho él, libre en su corto radio de acción, seguro de sus pequeños pies y manos desde que tenía cuatro años, consciente de la inmensidad de ciertos peligros y de la escasez de sus propias fuerzas.

$\mathrm{Y}$ así pensando el padre sigue mentalmente la marcha de su hijo. Pasa el tiempo. Se oye un balazo. Sigue el hombre con sus pensamientos y sus quehaceres, pero no vuelve el hijo a la hora debida. Pasa más tiempo y "el espectro de la fatalidad" comienza a levantarse. Por fin sale el hombre en busca de su hijo. ¿Qué pesadilla! "Ya antes, en plena dicha y paz, ese padre ha sufrido la alucinación de su hijo rodando con la frente abierta por una bala al cromo níquel." Pasa más tiempo, sigue andando el padre, llega el delirio. Aparece el hijo, cambian palabras de amor, y el padre ya:

... vuelve a casa con su hijo, sobre cuyos hombros casi del alto de los suyos, lleva pasado su feliz brazo de padre. Regresa empapado de sudor, $y$, aunque quebrantado el cuerpo y alma, sonríe de felicidad...

Sonríe de alucinada felicidad... Pues ese padre va solo. A nadie ha encontrado, y su brazo se apoya en el vacío. Porque tras él, al pie de un poste y con las piernas en alto, enredadas en el alambre de púa, su hijo bien amado yace al sol, muerto desde las diez de la mañana.

Se ve a las claras que este cuento es una repetición de $E l d e$ sierto. Otra vez nos hallamos frente al complejo de culpabilidad que no tenía Quiroga. Así él había expuesto a sus hijos a la vida de la selva y había insistido en métodos muy raros para educarlos. $\mathrm{Y}$ se ve también que el muchacho tiene interés sólo como móvil de la angustia del padre. Señalo el punto sólo porque demuestra que no siempre entra en la personalidad de las gentes, aunque estén formadas ya. El sufrimiento del padre es lo que verdaderamente llama la atención en este cuento.

Hay en tres narraciones adolescentes que son de particular interés, puesto que constituyen una representación en la literatura 
de episodios, más o menos importantes, en la vida de Quiroga. Son Una estación de amor, Pasado amor, e Historia de un amor turbio. Una estación de amor (II) cuenta un asunto de la juventud del autor. Nos ofrece la historia el espectáculo del amor puro y desinteresado de la adolescencia. Durante el carnaval, el joven Nébel (Quiroga) se enamora perdidamente de Lidia. El tiene diez y ocho años, ella catorce. "No había en su mutto amor más nube que la minoría de Nébel" pero "su padre... debía apuntar las íes con terrible vigor." En efecto, este señor, menos romántico que su hijo, se opone en absoluto al casamiento. La madre de Lidia era mujer de mala vida. Tomaba drogas y había sido la querida de su cuñado. A su vez, la madre se yergue contra la actitud del padre, y entre los dos, la madre de Lidia y el padre de Nébel, terminan "... el placer sin la más leve mancha, de un amor puro en toda su aureola de poético idilio." Años después, se ven otra vez Nébel y Lidia pero ya cambiados los dos acaba este cariño sórdidamente, no sin que veamos que ella al menos ha permanecido fiel espiritualmente a la memoria de su primer amor. ${ }^{18}$

La joven Lidia; a pesar de haber sido la causa de tanta pasión en Nébel, no tiene personalidad determinada. En la primera parte del relato, que presenta a la muchacha cuando tenía solamente catorce años, fuera de unas palabras sobre sus atractivos físicos no hay absolutamente nada. No habla directamente, y la única cosa que hace es escribirle a Nébel la carta con que rompe el idilio mostrándose sumisa y tímida: "Idolatrado Octavio: Mi desesperación no puede ser más grande; pero mamá ha visto que si me casaba con usted, me estaban reservados grandes dolores; he comprendido, como ella, que lo mejor era separarnos, y le jura no olvidarlo nunca, tu ... Lidia."

El centro de interés de este cuento es, como hemos notado, Nébel, joven romántico que sufre por el orgullo de su propia familia y el despecho de los parientes de Lidia. El autorretrato que pinta Quiroga aquí es sumamente atrayente desde el punto de vista psicológico. No puede admitir que los parientes de María Esther se hayan opuesto a él. En cambio, inventa un padre (el suyo había muerto) para decirnos que las objeciones vinieron de la familia de él, y además no deja de pintar con muy malos colores a la madre de su amada logrando así una especie de venganza. Otra cosa 
interesante es el hecho de que la Lidia del cuento hubiera permanecido fiel a su amor. La María Esther de la vida tampoco olvidó a Quiroga; pero hemos de notar de paso que según las ideas que se ven repetidas varias veces en la obra de Quiroga, ella tiene que serle fiel en la narración, sea por vanidad personal o tradición literaria. ${ }^{19}$

La ficción y la realidad de Una estación de amor se repitieron mucho después. Quiroga tenía unos cuarenta y seis años; la muchacha, diez y siete. Otra vez se opuso la familia de ella y como un adolescente Quiroga hizo todas las cosas posibles e imaginables para lograr lo imposible. Pero resultó que, una vez más, la familia de la muchacha la mandó a otro sitio fuera de "peligro". Con bastante fidelidad narra Quiroga los hechos en Pasado amor, haciendo cambios aquí y allá, como era su costumbre.

En la novela - se trata de una de sus dos novelas-, Quiroga se da el nombre de Morán. Cuando este Morán tenía treinta y un años, más o menos, fué a vivir a Misiones, con la joven con quien se había desposado. Se llamaba ella Lucila y sólo tenía dieciocho años. Encinta, se niega a ir a la ciudad a dar a luz. "Lo que afrontaba su marido en su ruda vida de hombre, podía afrontarlo ella también con sus fuerzas de mujer." ${ }^{20}$ La naturaleza, sin embargo, se ríe de estos romanticismos y Lucila muere de sobreparto. Sale Morán de Misiones. ${ }^{21}$

No habiendo bien ni mal que cien años dure, Morán vuelve dos años después para enamorarse de Magdalena, una muchacha de diecisiete años, hija de unos vecinos. Mala yerba, esta familia según la novela. (La Ana María de la realidad pertenecía, según Delgado y Brignole, “a la 'élite' comarcana.") ${ }^{22}$ La madre de Magdalena había ayudado a Morán cuando la muerte de su mujer. "Morán sólo recordaba en concreto que había respondido $N_{0}$ al pedido de la señora de que se colocara un crucifijo sobre el cadáver." ${ }^{23}$ Morán se entera de que la niña lo había defendido, después de la muerte de su mujer. Pero ¿ por qué lo hizo y por qué hubo necesidad de que lo hiciera? Porque lo querría, claro está, y porque habia chocado él con los sentimientos religiosos de la familia. Magdalena, flor sencilla y pura que crecía en el seno de esta familia de mala yerba, se enamora de Morán, o mejor dicho, no ha olvidado el amor que de jovencita había sentido. Pero hay diferencia entre la amistad 
y el amor, y si la familia de Magdalena permitía la una, no permitía el otro. Morán hace todo lo posible para mantener el contacto con. Magdalena, engañando a su familia por todos los medios clási$\cos$ y algunos nuevos. La muchacha, pura e inocente, "abría recién las pestañas a la luz, no tenía sino 17 años ..."; ${ }^{24}$ Sin embargo, con todo y su inocencia, se presta con la destreza tradicional de la mujer a todas las suertes del juego de amor. Se ve pronto que la verdadera batalla no queda en exterioridades sino en el corazón de la muchacha. E1 problema se plantea en esta conversación entre Morán y una amiga:

$\mathrm{Su}$ fanatismo.

-... ¿ Sabe lo único que me disgusta en Magdalena, Morán?

-No es fanática Magdalena.

-De Dios y la Virgen, no; pero sí de su madre, de su familia, de su incultura tradicional. Es la criatura más santa que yo he conocido. Y no me alegraría mucho, sin embargo, de verlo casado con ella.

- ¿Por quué, Inés?

- Porque usted es un Dios para ella, pero su madre es otro

Dios. Mucho cuidado, Morán. 25

Y en efecto Morán se da cuenta de la verdad de lo dicho. "E1 día en que deba decidirse entre su madre y yo, estoy perdido." ${ }^{26}$

Sigue la lucha trágica de la niña contra la voluntad de su familia. Por fin los parientes pretenden aceptar el casamiento aunque dicen francamente que al convertirse en mujer de Morán, la muchacha habrá muerto para su familia. Acepta Magdalena estos términos, pero agrega significantemente: "Sé que Dios me perdonará lo que hago." ${ }^{27}$ Llegado el momento final, Morán recibe una carta de ella: "Es inútil cuanto hemos hecho y hagamos - deciale más o menos Magdalena. - Estoy convencida de que para nosotros no hay salzación. Esta carta no me ha sido dictada por nadie; puedes estar plenamente convencido. Olvídame y adiós." 28

Ahora sí Morán se da por vencido:

A la presión católica, al terror del infierno, a la condenación de su alma, había confiado la familia su carta definitiva en el juego contra Morán... Jamás habían consentido los Iñíguez en ese matrimonio. Pero forzando con ello a Magdalena a decidirse entre Morán y el espectro de su madre arrastrada a las llamas del 
infierno por su proceder, Magdalena debía quebrarse, y escribir por su sola cuenta. Es lo que había hecho. ${ }^{29}$

Como Una estación de amor, está escrito Pasado amor casi exclusivamente desde el punto de vista del hombre. Magdalena habla de vez en cuando; pero no lo bastante para darnos muy buena idea de sus atractivos ni de sus pensamientos. El drama de la lucha de esta niña con su familia, se desarrolla puertas adentro, por decirlo así.

También como en Una estación de amor, la familia de la muchacha sale bastante maltratada en Pasado amor. Quiroga:

No comprendía el repudio que levantaba, a pesar de ser éste muy explicable. Aparte de la diferencia de edad, el sucididio de su mujer había contribuido a que se le tuviese en el concepto de hombre raro, seco, de convivencia imposible, y cruel hasta no permitir que se pusiera un crucifijo sobre el pecho de su esposa muerta. ${ }^{30}$

No sabemos exactamente lo que representa el hecho de que haya otra muchacha que sufre, en esta novela. Es Alicia Hontou con quien suele Morán buscar alivio en los momentos de desesperación de su amor hacia Magdalena. Para él, Alicia es un juguete, no más, mientras que para ella Morán es el objeto de todo su amor. Al saber que él piensa casarse con Magdalena, Alicia se envenena y muere. A Morán no le queda más remedio que abandonar Misiones, y así lo hace. ${ }^{31}$

Historia de un amor turbio, la otra "novela" de Quiroga apenas merece el nombre. Está hecha de muchas pequeñeces que acaban por fastidiar al lector hasta el último grado. Aunque el argumento no sugiera ningún hecho concreto de la vida de Quiroga, tenemos otra vez una especie de autorretrato en el protagonista, que se llama Rohan. Ya hablamos del amor que sentía la pequeña Eglé por él. ${ }^{32}$ Después de una ausencia de ocho años, Rohan vuelve a casa de ella. La pasión precoz de aquella niña enamorada no murió con la partida de Rohan. Pero ya no es niña Eglé sino señorita, y esta vez Rohan es quien se enamora en seguida. Encantados los dos, no parece haber problema; pero ellos crean un sinfín de dificultades ridículas. Sufre la muchacha. Sufre por no comprender que un hombre maduro tiene ciertas responsabilidades que no se 
pueden abandonar con el mismo entusiasmo romántico de los dieciocho años. Sufre porque a Rohan le interesa su trabajo. Sufre porque él tiene que acostarse por la noche. Pasan las páginas dedicadas a sus querellas con un sinfín de diálogos tan aburridos como. el que sigue:

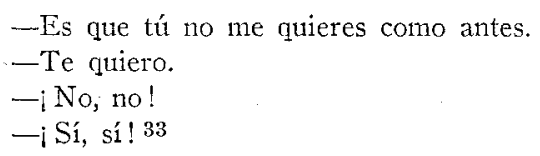

Rohan se propasa y se enfurece cuando Eglé se niega a hacer su capricho. Más sufrimiento para ella. Y Rohan, por su parte, tiene unos celos infantiles que le hacen llegar a frases de melodrama: "Cuando uno compra una cosa tiene el derecho de saber si ha sido usada o no!" "34 Se ccmprende que Eglé está "agotada" la mayor parte del tiempo. Por fin rompen y otra vez se va Rohan. Vuelve cinco años después, y encuentra a Eglé que ya no es niña ni jovencita sino una mujer formada, dueña de sí. Rico Rohan después de la muerte de sus padres, la madre de Eglé se interesa por él. Excusa a su hija. "¿Qué juicio quiere usted que tenga una chica a los diecisiete años?" " ${ }^{35}$ Pero ahora es tarde. Rohan "había comprado muy cara su felicidad actual para desear perderla." 36 .

Lo que llama la atención en Historia de un amor turbio no es. tanto la figura de Eglé. Exceptuadas la precocidad que se exhibe en la primera parte y su fidelidad al temprano amor, lo que tiene algo que ver con el ideal que Quiroga se formaba de la perfecta mujer, la muchacha parece enteramente normal. Es una jovencita ignorante, con las ideas propias de su edad en cuanto al amor. El verdadero centro de interés es Rohan, un neurótico de primera. Todas las dificultades que hay, él las crea, él mismo y la honradez o, si se quiere, la falta de vergüenza con que Quiroga analiza a las claras ciertas dificultades de su propio temperamento, atestigua su hostilidad contra todo lo que él creía hipocresía.

No vamos a decir que Quiroga habló de sí mismo en todos los. cuentos de amor. Otros muchos hay en que el hombre se contentó con estudiar el asunto con más objetividad. En Cura de amor (xII), por ejemplo, vemos una disección amarga de la crueldad y de la falta de comprensión de ciertos padres, ante las tiernas almas de 
sus hijos. Esta vez se trata de Fanny, una niña de quinice años. ¡Pobre Fanny! Desde los doce años "E1 río de su ternura corría sin cesar..."; es decir, que se enamoraba de todo el que llevaba pantalones, enfermedad bastante común entre las adolescentes en formación. La madre decidió "curarla" de una vez, para que tủviera, como le decía, "... un poco más de dignidad, no encaprichándose a cada paso como una sirvienta." Para efectuar el milagro, le echa a la cabeza al hermano de su yerno. El joven se finge enamorado perdidamente de la niña y ella, claro está, embelesada y encantada. Una noche el joven le pide su mano, y ella confiesa su amor delante de la madre que rompe a reír: "Todo ha sido una farsa, una farsa ¿entiendes?" $Y$ salen riendo con satisfacción la madre y el amante, mientras la niña se queda atrás llorando su desilusión y su vergüenza. Nada más dice Quiroga, y su silencio es elocuente.

Sabemos ya la gran atracción que tenían para Quiroga los casos raros. Encontramos muchos de ellos, en los cuentos que escribió sobre la adolescencia. Consideremos, por ejemplo, a la joven de Los guantes de goma (xII). Aquí se ve la neurastenia, en todo su horror. Muere un individuo de “... la más fúnebre viruela negra que es posible adquirir en la Aduana." Sigue la neurosis de su hija Desdémona. Durante un mes "... no vivió sino lavándose las manos." Siempre volvían a trepar los microbios. Consulta al médico, que explica el caso. Se trata de una monomanía. Hay que razonar, etc. Sale Desdémona feliz del despacho de esta maravilla de la ciencia. Ya comprende ella perfectamente la ridiculez de sus aprehensiones. "Diez minutos después el desesperado cepillo tornaba a destrozar la piel." Ningún efecto tienen las repetidas visitas a los consultorios hasta que el último médico encierra "... las manos en herméticos guantes de goma, ceñidos al antebrazo con colodiones, tiras y gutaperchas." Pero ¿no habrán quedado adentro uno o dos microbios? "A la mañana siguiente la madre, inquieta, levantóse muy temprano y halló al costado de la palangana todas las vendas ensangrentadas. Esta vez los microbios entraron hasta el fondo." Siguen cinco días de fiebre, y la muerte.

El infierno artificial (vI) es un cuento fantástico cuya estructura no nos interesa aquí. Pero debemos hablar de una muchacha de dieciocho años que aparece en la historia. Se enamora ella de "iun morfinómano, o cosa así" y por quién sabe qué anteceden- 
tes familiares o por la solidaridad en el amor, lee "... en veinticuatro horas cuanto es posible sobre hipnóticos" y se mete ella también en el "infierno artificial". Su especialidad no es ni la cocaína ni la morfina sinos los perfumes, que respira con delicia. "En veinte días, aquel encanto de cuerpo, juventud y elegancia, quedó suspenso del aliento embriagador de los perfumes. Comenzó a vivir, como yo con la cocaína, en el cielo delirante de su Jicky." Siguen los dos el camino de la degeneración física y moral varios meses, hasta que se consuma un pacto de suicidio entre ellos.

A mi modo de ver, no merece este cuento ningún comentario. Todo restulta artificial, melodramático, shocking. Se parece a los cuentos sensacionales sin arte ni interés que se pueden leer hoy en día, en cualquier folletín de periódico sobre jóvenes fumadores de marihuana. Es imposible sentir lástima de la muchacha.

Muy diferente es el estilo del cuento modernista y decadente que se llama Flor de imperio (vIII). Creo imposible leer esta historia sin que sugiera - muy a lo lejos, tal vez- algunos aspectos de la tragedia de José Asunción Silva. En temprana edad muere Divina, hermana del joven Rubén. "Rubén lloró largamente la desaparición de su hermana." Este llorar nos parece perfectamente natural; pero no el hecho de que el muchacho no deje de llorar. Se abandona al dolor $\mathrm{y}$ sólo le queda de positivo "... ese lánguido afán de ponernos tristes." Pasa el tiempo. Es hermoso Rubén, es gentil ; pero no se hace hombre. "El bozo que comenzaba a aparecer se detuvo en ligera sombra. Permaneció blanco, delicado, fraternal, como si el hombre que en él había hubiera fracasado de golpe a la muerte de Divina." Se ve que lo que le pasó a Rubén es exactamente opuesto a lo que le pasó a la Berenice del cuento del mismo nombre. Bajo una fuerte emoción, ella vive toda su vida espiritual en una noche; bajo otra emoción fuerte, Rubén deja de vivir. De mal en peor van las cosas. Todas las noches contempla el muchacho un retrato de Divina. "Y tanto su alma se llenaba de mujer, que al fin lloraba." Esta falta de energía masculina llega a tal grado, que por poco pierde Rubén los atributos del hombre:

Halló una muñeca de Divina, y con ella en los brazos pasó largos días en su cuarto, perdidos los ojos en el retrato adorado.

Sus formas se llenaban; cobró disgusto a los hombres. 
Por fin llega una mujer, y mientras "cruzaban a pasos tranquilos los campos llenos de luna", Rubén empieza a sufrir menos hasta que "una noche, más poética que todas, Rubén cayó de rodillas ante Luisa, y el resto de mujer que en él había disolvióse en llanto sobre las queridas manos consoladoras." Pero no tanto, sin embargo, porque "...en él las auras femeninas habían dominado mucho tiempo para dejar paso firme al hombre; el varón, apenas renacido, se dejaba ir a ensueños de idilios truncados, pañuelos desgarrados en los dientes, dichas mortuorias de inconsolables Julietas."

Al fin y al cabo, llegan las cosas a su destino inevitable: "Y una noche llenó de flores su cuarto, quemó blancas alhucemas y se tendió en la cama... Se cubrió hasta el mentón con la sábana, agotó en sus labios un ancho frasco de morfina, cruzó sus brazos bajo la cabeza, y el suave y sonrosado doncel, flor decadente del idilio, fijó los ojos en el techo, sonriendo."

No siempre son tan desesperados los casos raros. Se curan de vez en cuando, como todas las enfermedades. En La muerte del canario (VIII), por ejemplo, trata el caso de Blanca, una muchacha de quince años que se enamoró de su canario. Aquí la psicosis se comprende con facilidad. Se desarrolla la capacidad de amar, antes que se precise el objeto normal del querer. La niña se convierte en apasionada, por decirlo así, antes de convertirse en mujer. Nos pinta Quiroga el amor extraño de la muchacha y el canario, con toda su intensidad. Pero el pajarito muere y sigue la desolación de Blanca. Menos mal que llega su primo, Felipe. "La prometía ir a Montevideo, al teatro, a muchos paseos..." $\mathrm{Y}$ por fin "muere el canario" cuando Felipe le da a la niña el primer abrazo y el primer beso.

Un poco más complicado es el caso de La meningitis y su sombra (vi). Cae enferma de repente María Elvira, hermana de un amigo de Durán. Apenas la conoce éste. Una sola vez estuvo en su casa. Sufre la muchacha, se supone, "una meningitis, con todo su cortejo." Cualquiera que sea la enfermedad, la subconciencia de la muchacha toma el mando, y en el delirio prolongado parece sufrir de una sola obsesión, Durán. De buenas a primeras éste, que apenas la conoce, se ve "... convertido en sujeto gratuito de divagación cerebral, primero, y en agente terapéutico, después." Permanece Durán al lado de la muchacha siete noches consecutivas. Y 
desgraciadamente se enamora - de una sombra. Cuando vuelva al estado normal, ella no necesitará más de él. Situación absurda para Durán y divertida para el lector. Pero he aquí que una noche la muchacha inconsciente murmura al amigo de su delirio "... y cuando sane y no tenga más delirio... ¿me querrás todavía?" ¿Qué es esto? ¿Is there method in her madness? ¡Pobre Durán! Se cura la enferma y se enferma él. Pasan varios meses, durante los cuales Durán la ve y le habla de vez en cuando. Ella juega con este hombre -corrido, según Quiroga-, tonto para el lector. El no sabe declararse y decide abandonar la plaza, pero en el último momento encuentra palabras para declarar sti amor y todo termina bien.

Es curioso el efecto que nos produce este cuento. Los héroes amorosos de Quiroga actúan y piensan como adolescentes. Parecen reflejos del espíritu del autor. A pesar de sus treinta años, Durán es aquí el verdadero adolescente. La chica es joven; pero tiene toda la pericia en el amor que es tradicional en la literatura. E1 asunto del amor subconsciente de la muchacha para con un mero conocido, no está muy bien desarrollado, y en efecto nos parece sospechosa la tal inconsciencia y nos asombra tanto como a Ditán la famosa pregunta: "... y cuando sane y no tenga más delirio... ¿me querrás todavía?"

La tendencia didáctica no está muy marcada en la obra de Quiroga. Ya vimos en Cuentos de la selva la manera de dorar la píldora que tiene. Pero hay alguna que otra sentencia, alguno que otro cuento donde el autor habla directamente al lector o emplea algún símbolo transparente, para expresar tna idea u opinión suya. No olvidemos qụe Quiroga no sólo era escritor sino también maestro, y es natural que de vez en cuando este aspecto de su vida salga a la luz. Nos interesa aquí porque sus consejos se dirigen casi siempre a los jóvenes y porque la figura simbólica que emplea Quiroga en su método parabólico de enseñar, es generalmente un joven animal de alguna clase.

La abeja haragana ${ }^{37}$ es una versión reformada del viejo cuento de la hormiga y el saltamontes. Esta vez se trata de una abeja que no ve la necesidad del trabajo hasta pasar por "un duro aprendizaje de la vida." Dirige el autor algunas palabras a los jóvenes que le escuchan, por boca de la abeja: "Trabajen, compañeras, pensando 
que el fin a que tienden nuestros esfuerzos — la felicidad de todoses muty superior a la fatiga de cada uno. A esto los hombres llaman ideal, y tienen razón. No hay otra filosofía en la vida de un hombre, y de una abeja."

El león (I) cuenta la historia de un león joven e indomable a - quien los vecinos de una gran ciudad casan con una muchacha hermosa. Cambia el monarca de los desiertos su libertad por los refinamientos de la civilización. Le liman los dientes, le cortan las garras y ... deja de ser león. Pero llegado a la vejez se da cuenta de lo que ha perdido. Para él ya es tarde. No puede volver a la vida de antaño. Pero cuando menos lo piensa, la naturaleza le of rece un remedio. Tiene hijos, "leoncillos puros, libres de toda mancha." Ellos tal vez lleguen a ser el león que él no pudo ser. "El destino de las razas venideras era, pues, superior a su flaqueza de gordo león repleto que había trocado sus garras por un mantel,..." Y eI viejo león "los criaba [a sus hijos] en el más completo misterio, viviendo con ellos cuanto le era posible" hasta que "los llevó una noche de lluvia a las puertas de la ciudad, enseñándoles el desierto." El león vuelve a su vida de león fracasado. "Pero no importa. Allá iban sus hijos liberados, las salvajes fieras de garras y colmillos agudísimos, ya prevenidos desde el nacer; los cachorros redentores, suprema esperanza de los leones vencidos."

¿Menosprecio de corte y alabanza de aldea! I Jean Jacques Rousseau! ¿Qué desfile de ideas y reminiscencias literarias nos sugiere este cuento! Pero la cosa no es "literatura" porque sabemos que representa la creencia del autor, creencia a que trató de dar forma de vida. Este león ¿quién es sino Horacio Quiroga y qué representa él sino a los hombres de la "civilización" de hoy en día? Cansados ya, para nosotros no hay salvación sino por medio de nuestros hijos, quienes guiados por nosotros y protegidos por nosotros contra la farsa de la civilización de nuestro tiempo, podrán realizarse como hombres hasta un grado imposible para los que les hemos dado el ser. Y si no parece más práctico llevar a cabo estas ideas educativas en nuestro siglo que en el de Jean Jacques, a lo menos podemos decir que Quiroga, en la medida de su capacidad, trató de dar forma en Misiones y con sus propios hijos a sus teorías, lo que no se puede afirmar del autor de Emile. $\mathrm{Y}$ si nadie ha acusado a Qui- 
roga de tener sentido común, nadie tampoco lo ha acusado de ser hipócrita. Ya es algo. ${ }^{38}$

Juan Darién (IV) es otro animal, tigre, esta vez, que por uno de aquellos milagros tan comunes en la obra de Quiroga crece en medio de la selva que nosotros llamamos civilización. Parece que la viruela se llevó a todos los niños de un pueblo, y como es imposible vivir sin niños, una madre "adopta" a un tigre que ella considera como su propio hijo. Hazaña noble porque, como le dice una vieja serpiente (después de leer a Quiroga nos parece perfectamente natural el milagro de San Francisco), "Nada temas, mujer... Tu corazón de madre te ha permitido salvar una vida del Universo, donde todas las vidas tienen el mismo valor." Pero ¡helás! Juan Darién es "diferente", y a pesar de todas sus virtudes y de lo bueno e inocente que es, no permiten los buenos vecinos la diferencia. Así Juan tiene que salir de la sociedad de los hombres, para regresar a la selva. Se siente "humano" sólo para con la madre que lo aceptó, que lo protegió. "Tú sola supiste, entre todos los hombres, los sagrados derechos a la vida de todos los seres del Universo. Tú sola comprendiste que el hombre y el tigre se diferencian únicamente por el corazón." El odio, el prejuicio, la intolerancia, dice Quiroga, se convierten sólo en el sufrimiento de los inocentes como Juan Darién. Para la buena vida hemos de aceptar la idea de la fraternidad, sea entre los hombres, sea entre los animales, sea entre hombres y animales.

Otro mensaje se encuentra en La patria (Iv). Rige la vida de la selva la libertad. Pero llega un mal día en que deciden los animales imitar a los hombres. "Necesitan" una patria. ¡Adiós libertad! $\mathrm{Y}$ un viejo soldado que vuelve ciego de una guerra pro patria, explica el caso a su chico de ocho años. Nosotros juntamos algunas de sus frases, para dar clara idea de lo que este veterano creía necesario decir a su hijo:

La patria, hijo mío, es el conjunto de nuestros amores...

Cada metro cuadrado de tierra ocupado por un hombre de bien, es un pedazo de nuestra patria...

Traza, hijo mío, las fronteras de tu patria con la roja sangre de tu corazón. Todo aquello que la oprime y asfixia, a mil leguas de ti o a tu lado mismo, es el extranjero... 
Sólo los hombres de corazón ciego pueden hallar satisfechos todos sus ideales en los límites fatales de una sola frontera y un solo pabellón...

Todo hombre cuyo corazón late al compás de un distante corazón fraternal, y se agita ante una injusticia lejanísima, posee esta rara y purísima cosa: un ideal.

El hombre muere. "Pero no murió del todo, porque su tierno hijo recordó lo bastante de aquella noche para ser más tarde en la vida un hombre libre." Importan los hijos, entre otras cosas, porque les dejamos lo mejor que hay en nosotros - lo ideal. Así en $E l$ león y así en La patria.

El potro salvaje (IV) habla de un potro que corría "sin reglas ni medida", por el puro gusto de correr, que "se daba todo entero en sus disparadas salvajes." Sucedió que el potro fué a la ciudad "para vivir de sus carreras." Al principio la vida era difícil; pero por fin la gente comenzó a interesarse. "No corre por las sendas como es costumbre - decían-, pero es muy veloz. Tal vez tiene ese arranque porque se siente más libre fuera de las pistas trilladas." Pero se cansó el potro, por fin. Empezó a hacer sus cálculos, pesaba las ofertas, corría con más cuidado y por fin perdió el encanto de antes. Uno que lo había visto en la juventud, comentó: "Juventud y Hambre son el más preciado don que puede conceder la vida a un fuerte corazón." Y Quiroga da este consejo a los jóvenes que lo escuchan: "Joven potro: tiéndete a fondo en tu carrera, aunque apenas se te dé para comer. Pues si llegas sin valor a la gloria por pinguie forraje, te salvará el haberte dado un día todo entero por un puñado de pasto."

Los tres besos (IV) también es un cuento que Quiroga escribió para aconsejar a los jóvenes. Hubo un hombre que pospuso su deseo a cálculos de varias clases, hasta que por fin lo tenía todo; es decir: riquezas, honores, todas, todas las cosas que llegan al que lo piensa bien y despacio, al que actúa con cuidado y prudencia, en suma - las cosas que no se dan al apasionado e impetuoso. Sólo le faltaba una cosa al hombre: "el deseo, que había sacrificado con su juventud." Y sigue otro consejo directo de Quiroga: "Joven poeta, artista, filósofo: no vuelvas la cabeza al dar un beso, ni vendas al postrero el ideal de tu joven vida. Pues si la prolongas a su costa, comprenderás muy tarde que el supremo canto, el divino color, la 
sangrienta justicia, sólo valieron mientras tuviste corazón para morir con ellos." Vivir sin cálculos y con entusiasmo, es la única manera de vivir. $Y$ sólo los jóvenes son capaces de esta vida.

Creo necesario mencionar dos relatos en que Quiroga parece hablar de sí mismo y de sus hijos. El primero es Satisfacciones de la profesión de escritor (XIII). Es una protesta contra un proyecto de ley que limitara a diez años los derechos de los hijos a la herencia literaria del padre. Nota Quiroga que cualquier pobre diablo que llega a ser "propietario de un auto, una finca o una boquilla de ámbar, agradece a Dios el bien adquirido, porque está seguro de que todas las leyes divinas y humanas protegen su posesión." Luego considera el otro caso: "... quien posee ahora no es un pobre y simple buen hombre, sino un intelectual sin par, un escritor consagrado por el dolor y el genio... No hay miseria que ignore, ni tormento que desconozca... No se hallan en su libro rastros de imitación. De tal modo es su exclusivo bien; tan personales han sido sus sufrimientos, que el poema brilla fúlgido y aislado con luz hasta entonces desconocida." Pues bien, diez años después de la muerte de este hombre, "cualquiera puede beneficiarse de la herencia, editar, vender y ganar una fortuna, aun cuando falte hasta el pan diario a las criaturas del escritor." Pide Quiroga que el Estado adquiera los derechos de publicación, a los hijos del autor, comprando definitivamente su obra o garantizando un porcentaje del dinero ganado por la publicación de la dicha obra. No me parece tan interesante aquí el cuidado natural de un padre por el porvenir económico de sus hijos, como el concepto que tenía Quiroga de la relación íntima entre la vida personal del autor y la obra escrita.

Tal vez de mayor interés general es Sin salida (xIII). Quiroga aquí trata un problema que es la pesadilla de todos los padres de nuestra época. Había conocido Quiroga a Jack y a sus padres. E1 papá era inglés; la madre, uruguaya "aunque de origen y educación perfectamente británicos." Los padres, “... serenamente convencidos de nuestra falla sudamericana: falta de ideal, cobardía para el trabajo, e ironía criolla, habían criado y formado a su hijo único pensando siempre en la vieja y noble Inglaterra ..." Cuando Jack tiene ocho años, vuelven a Inglaterra. Viene la guerra de $1914 \mathrm{y}$ Jack, con diecisiete años ya, sienta plaza de voluntario. Sus padres esperan el gran día de saludarlo en la estación cuando vuelva; pero 
"Lo que venía en el mismo tren esperado, era el cadáver de la criatura en un cajón."

No por ser común, deja de tener interés el caso. Escuchemos al padre de familia que era Quiroga:

Ahora, pienso yo: ¿qué sentirán los padres en el fondo de su alma? Es posible que se pierda un hijo único, una criatura de 17 años, sano, alegre, feliz, sin que se escarbe en los más hondos rincones de la desesperación por no haber sabido conservar la vida de esa criatura?...

No sé. Sé que tengo dos hijos, uno de ellos varón. $\mathrm{Y}$ este otro Jack de cuatro años, a quien no educo ciertamente en el culto de la civilización actual, irá un día a aprender a hacer trincheras, y no volverá. Por más honda que pueda ser la infiltración de las ideas de un hombre libre, al tener 17 años correrá con sus compañeros, y no volverá.

¿Qué hacer, pues,...?

En estas consideraciones sobre los jóvenes de sus libros, no debemos olvidar que Quiroga era el más grande niño de todos. Hombres hay que nacen viejos y otros hay que mueren jóvenes. Del último grupo, en cierto sentido, forma parte Quiroga. Después de todo ¿qué es la cosa que llamamos crecer? Para los más es perder poco a poco los entusiasmos de la juventud. No siguió este camino Quiroga. Hasta el fin guardó la vitalidad que lo destaca de entre los suyos. Larguísima es la lista de sus aficiones, y a muchas de ellas se refiere en sus obras. El espíritu que se revela en todas éstas es el de un hombre que no se cansó, a pesar de las dificultades; un hombre que tenía siempre el sentido de lo maravilloso de las cosas; un hombre cuyo espiritu se negó a envejecer. Para él, lo importante fué siempre la formación de las cosas, nunca la forma acabada. Esa pasión de hacer cosas con las propias manos, la interminable serie de experiencias, la creación, por decirlo en una palabra, tenían para él una importancia infinitamente más grande que la de vanagloriarse por lo acabado. Y tal vez sea eso finalmente la causa de su gran interés por los seres en formación que acabamos de estudiar. Muy poco sitio tienen los viejos en las obras de Quiroga, ya que carecen de vitalidad. Quien deja de renovarse deja de vivir y los viejos no se renuevan. Puede ser que esto explique, hasta cierto punto, la susceptibilidad de Quiroga para las muy jóvenes, en los 
asuntos del corazón. Todos conocemos ejemplos de esos tipos que creen haber descubierto la mágica fontana de la juventud. $Y$ ¿la prueba? Siempre saben capturar corazones jóvenes. Durante todo el curso de su vida se negó Quiroga resueltamente a "grow up". Fracasó en la vida escolar, por falta de ganas. Malgastó la fortuna heredada de su padre. Debido a él en gran parte, termina su primer casamiento en la tragedia del suicidio de su primera mujer. Ama con pasión a dos jóvenes, y las pierde por no poder convencer a sus familias de su seriedad. Se casa, en segundas nupcias, con una niña casi treinta años menor que él, y esta segunda mujer efectivamente "lo deja". Como los niños, es capaz de trabajar mucho si le interesa el asunto; pero si no tiene interés, es incapaz de hacer nada. Ha de tener razón. No admite opiniones contrarias. Quiere lo que quiere y ya. Sería posible pero inútil seguir la lista. En su obra Quiroga habla mucho de sí, y a menudo vemos evidencias de su comportamiento, a veces infantil, en la vida.

Un escritor de la talla de Quiroga, merece que lo estudiemos a fondo y no sólo en sus aspectos más obvios. Mucho se ha escrito, en términos generales, sobre los temas de Quiroga y poco sobre los medios empleados por él para realizar su expresión. Este ensayo ha señalado en forma más o menos detallada uno de estos medios, la constante explotación de la juventud como fuente de inspiración literaria.

Una de las características del artífice maestro es que sabe crear maravillas de construcción y de hermosura, con toda clase de materias primas. Ahora bien, en el cuento Quiroga fué maestro y stupo emplear todo lo que tenía a mano para lograr efectos sorprendentes. La vida y la inclinación lo llevaron al contacto con seres jóvenes de todas las edades, y como nunca separó la vida propia del arte - cosa facilísima de probar-, no sorprende que se haya servido de estos jóvenes en su obra. Así es que en sus libros nos encontramos con reflejos de la propia juventud, con reminiscencias de su propio pasado de profesor, con un mundo de recuerdos de su vida de padre de familia, frente a los problemas no sólo de orden práctico sino también afectivo y emocional, que se presentan a todos los padres. $\mathrm{Y}$ cuando fallan todas estas fuentes personales de inspiración, siempre quedan las lecturas. 
Dados los grandes temas (vida familiar, amor, locura, muerte, análisis psicológico, etc.), nos quedamos frente al problema técnico - la utilización de la materia prima. Quiroga tuvo que adap-tarse aquí a las particularidades de la materia. Sigue la naturaleza, en la explotación de sus asuntos. Así es que cuando escribe de los niños de pecho y de los de la primera infancia, habla no de las reacciones personales de ellos sino del efecto que tienen en los demás. Se aprovecha del hecho de que los muy pequeños tengan un poder fuera de toda proporción, cuando se trata de sus padres. Por ellos sufren y gozan los grandes. $Y$ aun en los que no tienen los lazos de la paternidad, sugieren problemas filosóficos y religiosos porque cuando ellos enferman, sufren y mueren, todo hombre que piense se ve cara a cara con el dilema de la muerte y del sufrimiento, no de los pecadores que son los grandes sino de los inocentes que son los jóvenes. Los niños que llegan a la segunda infancia, están expuestos a los mismos peligros que les quitaron los hermanos; pero además tienen otro y es que deben hacerse hombres, instruirse, educarse, civilizarse. Como hemos visto, el proceso no siempre es agradable. Al contrario, es a veces sumamente penoso por ser tan absurdo, $\tan$ falso, tan hipócrita el sistema de vivir de los grandes. De vez en cuando, estos principiantes sufren por ser precoces y vemos los estragos que causan en el cuerpo y en el alma de los chicos las batallas sentimentales y morales de los mayores. La llegada a la adolescencia, etapa final de la niñez, es todavía más interesante. El hacerse grande no es tan fácil, aun cuando todo nos parezca normal. No llega uno a serlo de la noche a la mañana ni crecen con la misma velocidad lo físico y lo moral del ser humano. El tener cuerpo de hombre o mujer, no es todo lo necesario para hacer de uno un hombre hecho y derecho, ni una mujer madura y sensata. La adolescencia es la edad de los nervios crudos y de una gran intensidad de sufrimiento, especialmente en los casos anormales que interesaban tanto a Quiroga. Ya vimos hasta qué punto el drama del cambio de la juventud a la madurez ha sido utilizado como recurso artístico por él.

Una gran parte del genio de Quiroga se ve en la capacidad que tenía de adaptar a los usos de la literatura materiales de muy varia procedencia. Todo - o casi todo-, visto por los lentes especiales del autor, llega a ser asunto literario. Cosas de su vida, de la 
de sus parientes o conocidos, cosas imaginadas, memorias literarias; todo se presta a la explotación literaria y artística. Si todos somos algo egoístas, Quiroga lo era mucho, y no nos extraña ver que él mismo bajo uno $\mathrm{u}$ otro aspecto aparezca como protagonista de sus obras. A pesar de todo, el centro de interés de sus escritos es el pensamiento, la acción, la manera de ser de Horacio Quiroga. Los personajes de las obras reflejan turbiamente a veces, a veces a las claras, la personalidad de su creador. Así es que los infants, los niños y los adolescentes interesan no tanto por sí mismos como por lo que reflejan de Quiroga. No quiere esto decir que la obra de Quiroga tenga sólo este valor biográfico. Sólo deseo afirmar que vive no simplemente la vida particular e inhumana de todos los monumentos artísticos sino que también vive como documento humano revelador de la intimidad espiritual del artista. Quiroga era un hombre para quien los pequeños existían, y el uso que hizo de ellos como instrumentos de la expresión de sus propios sentimientos, de sus propias ideas, es una de las cosas que lo apartan de la corriente de las letras hispanoamericanas. Escaso es el papel que desempeñan los niños en la literatura de Hispanoamérica; pero en Horacio Quiroga, cualquiera que sea la manera del momento, escriba él en estilo familiar, filosófico, psicológico, pedagógico o simplemente como costumbrista, hay grandes posibilidades de que aparezca uno o más de los jóvenes casi omnipresentes en su obra.

$$
\begin{aligned}
& \text { Gordon B. RAY, } \\
& \text { Wayne University, } \\
& \text { Detroit, Michigan. }
\end{aligned}
$$

\section{$\mathrm{NOTAS}$}

1 Para este ensayo he utilizado la edición de los cuentos de la "Biblioteca 'Rodó' ". (Montevideo: García y Cía., ?-1945, tomos I-Xim.) El número que doy al mencionar un cuento es el del tomo en que se puede encontrar.

2 Quien se pone a leer alguno que otro cuento de Horacio Quiroga se interesa, como es natural, por el cuento mismo. Quien lee algunos más, empieza a ver en ellos la personalidad del autor. $Y$ quien lee todos, termina por olvidar poco a poco la literatura, para examinar con interés creciente el autorretrato que pinta aquella rara avis que era Quiroga. Así es que cuan- 
do el autor de estas páginas empezó a estudiar la materia que se trata en ellas, pensaba hacerlo desde un punto de vista puramente literario y estético. Pero cuanto más se desarrollaba el trabajo, menos seguridad tenía de ir por buen camino: “. . . todos los temas parecen sugerir algo de la vida misma del autor, como si en el desarrollo de las ideas hubiese un índice capaz de revelar cuál fué la consagración más íntima y el sentido profundo de esa vida." (Antonio M. Grompone, "El sentido de la vida de Horacio Quiroga", p. 15, en Horacio Quiroga, Los arrecifes de coral. Montevideo: Claudio García y Cía., 1943.) Quiroga es un escritor que entra en su obra hasta tal punto, que es difícil saber, a veces, lo que representa una realidad de su existencia, lo que es solamente una invención de su espíritu y lo que indica una influencia literaria. Una cosa sí es cierta: divorciar la obra de Quiroga de su vida, es absolutamente imposible, aun. cuando nos interesemos solamente por la estética. Si hablamos, entonces, de la vida real de Quiroga en las páginas que siguen, será para mejor entender el sentido y la dirección de la obra qu consideramos.

3 Tuvo tres hijos: Eglé, nacida en 1911; Dario, 1912; y otra hija de la segunda mujer, en 1928.

4 Empieza a llorar el nene de un cuento y el padre reacciona a la manera de todos los padres desde los primeros días de la vida humana: "¿Enfermo?... ¿Hambre?... ¿Pañal plegado, alfiler abierto? No. ¿Qué entonces?" (El machito, xur). Una mujer no hace tal o cual cosa. ¿ Por qué? “... dos chicos no dan mucha libertad a la madre..." (Muy caro: dos pesos, xiI). Observaciones no muy profundas o filosóficas, si se quiere; pero detalles que llevan el sello de la verdad. Quien se fija en tales pequeñeces, ha de ser miembro acreditado del círculo de los padres.

5 John A. Crow, "La obra literaria de Horacio Quiroga", vir, 19 de la edición de los cuentos a que me refiero en 1 .

6. Horacio Quiroga, Pasado amor. (Montevideo: Claudio García y Cía., 1942), D. 47.

7 Véase Maurice Maeterlinck, L'Hôte Inconmu. (Paris: Charpentier, 1917), pp. 125-131.

8 Quien sepa algo de la vida de Quiroga, sabrá que buenas razones tenía para su preocupación con la fatalidad de la muerte. Apenas tiene dos meses de edad cuando su padre muere de un balazo accidentalmente disparado delante de la madre, que tenía al pequeño Horacio en los brazos. Desmayo de la madre. Caída de Horacio. Después la madre vuelve a casarse. El padrastro se suicida. Luego el joven Quiroga, por accidente, mata a uno de sus mejores amigos con una bala de pistola. Su hermano Prudencio muere en circunstancias trágicas. Su primera mujer se suicida. Toda la vida del hombre sugiere el horror de la muerte imprevista, violenta, rápida. "En el corazón humano no hay una pulsación misteriosa que haga prever el aconte- 
cimiento fatal que va a aniquilarlo. Nada en el cielo, ni en las cosas miradas, ni en la tierra hollada, advierte al hombre que el universo entero se desplomará sobre él." (Pasado amor, p. 136). Pero todavía no hemos llegado al fin de esta serie de tragedias. El mismo Quiroga se sucidida, y como si Dios no quisiera que se quedara tranquilo en la tumba, su hija Eglé se mata, dos años después. "La muerte, una muerte como muchas veces nos encontramos en sus libros desconcertantes, lo acompañó siempre, silenciosa y fatal, como un perro adicto, siguiéndolo paso a paso en sus aventuras, y envolviéndolo en una especie de penumbra traslúcida atravesada por lívidos reflejos." (Alberto Lasplaces, "Horacio Quiroga", I, 16 de la edición de los cuentos a que me refiero en 1 ).

9 José M. Delgado y Alberto J. Brignole, Vida y obra de Horacio Quiroga. (Montevideo: Claudio García y Cía., 1939), p. 195. Es indispensable este libro, para comprender a Quiroga.

10 Horacio Quiroga, Historia de un amor turbio. (Montevideo: Claudio García y Cía., 1943), p. 23.

11 Ibid., p. 24.

12 ¿Cuál es la explicación de este gran interés que tenía Quiroga por el tema del amor precoz? ¿Es una cosa puramente literaria, inspirada en la obra de otros, tal vez de aquellos rusos que le interesaban tanto? Si fuera asi, no sería nada típico de Quiroga que se introducía él mismo en sus relatos con tanta frecuencia. Es más probable que los cuentos tengan alguna referencia a la propia vida, aunique no estamos seguros de cuál sea. Hay que fijarse en el paralelismo de los cuentos. En cada caso se trata del amor precoz de una niña, y no de un niño. En cada caso, la niña queda fiel a este primer amor. En cada caso, el hombre es mucho mayor que la niña. ¿ Le gustaba a Quiroga imaginarse el héroe de tal amor? Como sabemos que él mismo había sufrido tales amores de niño, ¿adquiere un sentido especial el hecho de que las enamoradas de los cuentos sean niñas y no niños? Diría un psicólogo, tal vez, que en la vida real Quiroga buscaba inconscientemente la clase de amor en que el objeto llega a ser, para el enamorado, una especie de dios. ¿Reflejan los cuentos subconscientemente la convicción de que sólo los niños son capaces de ver la perfección en la persona amada? Una frase del joven Quiroga sugiere tales ideas: "Nos hacemos grandes al recordar que un sencillo y tierno corazoncito guarda y ama la imagen vulgar de cualquiera de nosotros." (Diario de viaje a París de Horacio Quiroga, p. 46. Edición de Emir Rodríguez Monegal, Montevideo: número, 1950). Linda materia hay aquí para un ensayo a lo freudiano, para explicar todo esto; no siendo psicólogo, me limitaré a sugerir el problema y el interés del tema. Sabemos que Quiroga se enamoró de una de las alumnas de la escuela normal donde enseñaba y que la hizo su mujer. También sabemos que se casó por segunda vez con una muchacha de veinte años teniendo él cuarenta y nueve. Lo demás se halla sugerido. 
13 Es posible que este cuento, tan raro, provenga de una conversación a bordo del vapor en que Quiroga viajó a Francia. Hablaba con una "gringota" y su hija. "Cuenta la madre que [la hija] lloraba cuando aprendía ciertos trozos de ópera. - ¿Porque no le gustaban? -No, perque despertaba i sentimenti. E molto sensibile mia figlia. (Diario, p. 53.)

14 Horacio Quiroga, Cuentos de la selva (para niños). (Montevideo: Claudio García y Cía., 1943), "E1 loro pelado."

15 Ibid., "La gama ciega." Los mandamientos son sensatos y algo divertidos. "Hay que oler bien primero las hojas antes de comerlas, porque algunas son venenosas." "Cuando se come pasto del suelo, hay que mirar siempre entre los yuyos para ver si hay víboras."

16 Hay que exceptuar a los padres de familia como Quiroga.

17 Cuentos de la selva, "Historia de dos cachorros de coatí y de dos cachorros de hombre".

18 Hemos dicho que Una estación de amor es una representación literaria de un episodio real de la vida de Quiroga y lo interesante es ver lo mucho que cambia los hechos. Siendo él mismo el protagonista, no nos extraña que Nébel sea el centro de interés del cuento. Lidia fué en la vida real el primer gran amor de Quiroga. Se trata de un episodio sucedido en Salto, en el carnaval de 1898. La muchacha se llamaba María Esther, según los amigos de Quiroga. (Véase Delgado y Brignole, op. cit., p. 79.) El espléndido idealista romántico del cuento, no es según estos mismos amigos el verdadero Quiroga, ni era éste el buen partido fuera del alcance de la familia de la muchacha que aparece en la ficción. Me permito citar un párrafo de su libro, para indicar lo que pensaban unos testigos de la situación. Dicen ellos que nuestro autor era:

... un amante que en algunas oportunidades demoraba las despedidas como quien, embelesado, ha perdido la noción del tiempo $y$, en otras; se encasquetaba furiosamente el sombrero y partía dando portazos: no revelaban seguramente a ningún futuro arquitecto de dicha conyugal.

... Para sufrir el sacrificio de soportar aquel temperamento arbitrario y reacio a cualquier buena convivencia, el joven no podía ni siquiera of recer el halago de una posición bien consolidada. Su fortuna estaba ya bastante menguada, y, fuera de su inclinación por las bellas letras, que no daban de comer a nadie, no se le conocía ninguna actividad positiva, ni aun un propósito de trabajo capaz de ofrecer a un hogar alguna esperanza de solidez y estabilidad. Al contrario: daba la impresión de que jamás se sujetaría a ningún oficio lucrativo ni a método alguno, y usaba de sus bienes con tal despreocupación y largueza de mano que, si algo podía profetizarse comó seguró, era la bancarrota a no muy largo plazo. (Delgado y Brignole, p. 82.) 
19 En 1920 apareció Las sacrificadas, drama basado en el mismo asunto que Una estación de amor. Los méritos de la obra son escasos y no ofrece bastantes diferencias del cuento para que la estudiemos aquí.

20 Pasado amor, p. 16.

21 No puedo menos de decir unas palabras sobre la forma muy típica en que Quiroga ha cambiado aquí los hechos reales que le dan las bases de su novela. Lucila representa a la primera mujer de Quiroga y no murió ella de sobreparto sino que se suicidó. También notamos que la mujer de la novela quiere que su hijo nazca "naturalmente". La verdad es que el parto "natural" fué una de las ideas de Quiroga y no de su mujer. Delgado y Brignole hablan de "su oposición a la presencia de comadronas y a adoptar medidas precaucionales" (p. 209), y nos dicen que para él "se trataba de un episodio biológico normal, común a todas las hembras mamíferas, a quienes la naturaleza, sin ayudas ajenas, desembaraza con absoluta idoneidad." (p. 208). ¿Es este cambio otra indicación de un complejo de culpabilidad?

22 Delgado y Brignole, op. cit., p. 260.

23 Pasado amor, p. 32.

24 Ibid., p. 75.

25 Ibid., p. 88.

26 Ibid., p. 92.

27 Ibid., p. 128.

28 Ibid., p. 137.

29 Ibid., pp. 137-138.

30 Delgado y Brignole, op. cit., p. 264.

31 Sería de mucho interés saber lo que significa Alicia para Quiroga. Rompe la unidad del libro la apariencia de este personaje innecesario. ¿Es que Quiroga se divirtió pintándose como un tenorio del desierto cuyos encantos ninguna muchacha podía resistir? No hay manera de resolver el problema, que yo sepa, puesto que ignoramos si Alicia es otro elemento de la realidad que emerge de la novela o solamente una invención. De todos modos, no sirve a ningún fin artístico visible.

32 Véase p. 286.

33 Historia de un amor turbio, p. 82.

34 Ibid., p. 98.

35 Ibid., p. 111.

36 Ibid., p. 112. 
37 Cuentos de la selva, "La abeja haragana".

38 Lo que Quiroga parece no haber admitido es que a veces los hijos también tienen ideas suyas sobre la propia vida. Delgado y Brignole hablan de la llegada de Quiroga a Buenos Aires la última vez. Pide un beso a la hijita que acompaña a su mujer a saludarlo. "La pequeña se le aproximó entonces y, antes de besarlo, le clavó en el alma estas palabras, dolorosas para él como espinas : 'no quiero volver más a Misiones'." (p. 384). 